\title{
Reflexões sobre o método nas ciências e o ensino de ciências
}

\author{
Marco Aurélio Nicolato PEIXOTO ${ }^{1}$ \\ Ierecê BARBOSA ${ }^{2}$ \\ Dayse Peixoto MAIA ${ }^{3}$
}

\begin{abstract}
Resumo: O presente ensaio aborda a necessidade de uma integração entre os paradigmas que enfocam o ensino de ciências, no sentido de que a aparente dicotomia paradigmática existente entre eles gera uma situação conflituosa para o aluno, ao abordar temas de vanguarda nas ciências, que podem encontrar amparo em ambos os enfoques. Trata-se de dois paradigmas capazes de se integrarem mutuamente, um de cunho mais objetivista, em que prevalece o empirismo e as pesquisas cognominadas quantitativas e outro mais subjetivista com preponderância da fenomenologia, sustentando as pesquisas chamadas qualitativas. $\mathrm{O}$ percurso metodológico foi embasado em pesquisa bibliográfica tendo como base Apolinário (2009), Serrano (1998), Sanches (2007), Davydov (1998), Leontiev (1983) dentre outros, e na observação participativa em sala de aula. Os resultados apontam para a necessidade de um campo educacional devidamente estruturado, em que o discente construa, a partir da autonomia, um caminho "livre" em termos paradigmáticos e metodológicos, por via de uma atuação pedagógica apurada e a utilização dos meios e recursos disponíveis pelas duas correntes. Esse conjunto de estratégias combinadas pode se configurar em um importante método a ser desfrutado, tanto pelas ciências em sua origem intrínseca, quanto pelo seu ensino, trazendo condições e provocando uma postura que poderá ajudar na reflexão e na compreensão dos conceitos de complexos da ciência contemporânea, importantes na cognição dos alunos.
\end{abstract}

Palavras chave: Metodologia qualitativa. Metodologia quantitativa. Ensino de Ciências. Objetivismo. Subjetivismo.

\section{Reflections on methods in science and science teaching}

\begin{abstract}
This essay addresses the need for an integration between the paradigms that focus on science education in the sense that the apparent dichotomy between them paradigm generates a conflict situation for the student to address issues of lead in the sciences, they can find shelter in both approaches. These are two paradigms capable of integrating with each other, one of a more objectivist, in the prevailing empiricism and quantitative research nicknamed subjectivist and another with a preponderance of phenomenology, arguing calls qualitative research. The methodological approach was based on a literature based on Apolinário (2009), Serrano (1998), Sanchez (2007), Davydov (1998), Leontiev (1983) among others, and participant observation in the classroom. The results indicate the need for a properly structured educational field, in which students build, based on autonomy, a way "free" in terms of paradigmatic and methodological approaches, through a pedagogical performance and accurate use of available means and resources by two chains. This set of combined strategies can be configured in an important method to be enjoyed by both intrinsic science in its origin, as its teaching, bringing conditions and causing a stance that could help in the analysis and understanding of the concepts of vanguard of contemporary science important in the students cognition.
\end{abstract}

Key-words: Qualitative methodology. Quantitative methodology. Science Education. Objectivism. Subjectivism.

\footnotetext{
1 Bacharel/Licenciado em Ciências Biológicas e Pedagogo. Mestre em Tecnologia da Educação (CEFET-MG). Doutorando da Rede de Educação em Ciências e Matemática da Amazônia - REAMEC. Professor da pós-graduação Latu sensu de Educação em Ciências do Instituto Federal de Educação, Ciência e Tecnologia do Sul de Minas (IFSULDEMINAS). Inconfidentes, Brasil. E-mail. [aur.nico@bol.com.br]

${ }^{2}$ Pedagoga, Bacharel em Comunicação Social, Psicanalista Clínica, Doutora em Educação. Professora de Pesquisa em Educação em Ciências e Matemática da Rede de Ensino de Ciências e Matemática - REAMEC. Manaus, Brasil.

${ }^{3}$ Licenciada em Ciências Biológicas. Mestre em Educação em Ciências. Doutoranda da Rede de Educação em Ciências da Amazônia - REAMEC - Manaus, Brasil.
} 


\section{Introdução}

$\mathrm{O}$ entendimento de que é através do ensino da ciência que o educando aprende a descobrir seu mundo, a esclarecer suas dúvidas, valorizar a vida e o ambiente que o cerca, ao mesmo tempo em que se prepara para ser agente influenciador e transformador da realidade na qual está inserido, parece ser inquestionável. Nesse sentido, pouco importa então, que o ensino seja considerado como um processo no qual se pretenda levar o aluno à descoberta de fatos, à busca de leis para explicação dos fenômenos e ao enriquecimento dos conhecimentos a respeito da natureza, ou mesmo como um corpo sistemático de conhecimento registrado e preservado, obtido através de observação, experimentação e estudo.

No decorrer do processo de ensino em que se busca provocar no aluno o desenvolvimento da capacidade crítica e transformadora, o conteúdo de determinadas áreas atinentes ao estudo de ciências nos desafiam e nos colocam entre duas realidades, uma que se diz objetiva e outra, cognominada subjetiva. Fenômenos como a apoptose (nota 1), a heurística metabólica (nota 2), a geração de um campo magnético a partir de um campo elétrico, entre outros acontecimentos, remetem-nos a uma reflexão mais aprofundada sobre as bases nas quais se assenta a vida.

Nesse patamar, o limiar das duas realidades se configura intensamente. Uma delas física, mais concreta, na qual a ciência vem se debruçando há muitos séculos à luz da pesquisa quantitativa e outra de natureza subjetiva, estudada mais à luz da pesquisa qualitativa, ambas, no entanto, se relacionando igualmente no mundo objetivo. No campo de natureza mais subjetiva, aspectos não visíveis regem fenômenos fisiológicos importantes para a manutenção da vida, como os fenômenos de difusão (nota 3), osmose (nota 4), atração entre cargas elétricas opostas. Somam-se à observação destes, diversos outros fenômenos insertos no âmago das ciências e que são também objetos de ensino da mesma.

Tais situações sempre suscitaram reflexões e nos levaram a levantar questionamentos, o que vem ocorrendo com maior intensidade e de forma recorrente, nesses últimos sete anos, durante as aulas nas disciplinas de Bioquímica, Biofísica e Citologia, lecionadas para várias turmas em cursos como o de graduação em Ciências Biológicas e Educação Física, dentre outras em que atuamos como docentes.

\section{Percepções Diferentes}

No que diz respeito a relação entre o objetivo e visível, mensurável com certa exatidão e o subjetivo, passível de intuição, no que concerne a suas causas intrínsecas com menor mensuração tradicional, duas grandes referências se estabelecem, tais como nuvens distintas. Uma delas situando-se em relação ao "mundo mais objetivo", que estaria 
amparado nas ideias positivistas e pós positivistas, com destaque para as de Apolinário (2009), ao afirmar que "uma pesquisa tem alta validade interna quando proporciona inferências causais sólidas, o que normalmente ocorrerá apenas em pesquisas do tipo experimental" (Apolinário, 2009: 114). Ao mesmo tempo, a outra, pairando sobre o "mundo mais subjetivo", que estaria amparado pelas teorias holísticas e da complexidade, percebidas nas ideias de Serrano (1998), ao afirmar que,

el estúdio de casos predominantemente de carácter cualitativo, radica em el hecho de que este diseño se elige precisamente porque los investigadores están interessados em La intuición, el descubrimento y la interpretacion más que em La comprensión de hipótesis (Serrano, 1998: 82).

O evento científico alvo de estudo e de ensino se localiza na interseção destas duas realidades amparadas por paradigmas e métodos distintos, mas que, segundo Sanchez (2007), se complementam. Ou seja, para ele os "recurso de diferentes abordagens, as quais não só ampliam e complementam os conhecimentos sobre uma determinada problemática, senão que são passíveis de uso simultâneo" (Sánchez, 2007: 99-100).

Diante do pseudo paradoxo, no momento em que se busca um entendimento que venha se interpor entre as concepções objetivista e subjetivista, delineamos um novo tempo para a humanidade. Um novo tempo em que haverá o reconhecimento do invisível atuante sobre o visível. Em que se saiba que observamos apenas "meias verdades", entre as quais, digamos assim, uma externa regida por um pensamento mais empirista e outra interna regida por um pensamento mais intuitivo, atingida pela reflexão e pela intuição.

Comparamos este momento à época das grandes descobertas marítimas, quando as naus possuíam tecnologias que lhes permitiam se deparar com algo novo a qualquer momento, como de fato se deu com o evento da descoberta das Américas. Com os avanços das tecnologias atuais, levando-se em conta a física quântica e estudos aprofundados de órgãos importantes como o cérebro, poderemos ir além, e inferir, cada vez mais, a presença de uma outra realidade paralela, a objetiva tridimensional, plasmada pelas ideias e na qual o pensamento possui papel gerador, legítimo e principal.

\section{Considerações de aspecto cognitivo}

Ao se falar em pensamentos, ideias e conceitos em ciências não poderíamos deixar de tecer algumas considerações em relação a cognição como processo que envolve todas essas questões entre muitas outras.

Uma ênfase maior tem sido dada ao estudo dos aspectos da cognição ligados aos mecanismos da linguagem. Tal fato se justifica tendo em vista que autores destacados como Luria (1981) e Bakthin (1992), por exemplo, consideram a cognição como expressão do pensamento e de uma contextualização com feições sociológicas. No entanto, a relação entre ciência e cognição 
vem se expandindo dia a dia, assim como o entendimento de seu órgão mais nobre: o cérebro, otimizando um novo campo de estudo. Tal campo congrega várias áreas e recebe a cognominação em seu sentido mais amplo de neurociências.

Um longo processo cognitivo, de acordo com as ideias de Riedl (1982), levou a uma compreensão de mundo que possibilitou em última instância a sobrevivência da espécie. Este processo, segundo ele, envolve a adaptação e a aprendizagem genética durante a filogenia (nota 5). O ser humano então na resolução de problemas se utilizaria de dois caminhos, sendo um de racionalidade e reflexão consciente e o outro de formas inatas de ideação baseado em raízes filogenéticas Riedl (1984). Somando-se a esta concepção Lorentz (1969), define a vida como um processo energético e cognitivo que lida com informações do ambiente.

De acordo com as ideias de Garcia (2005: 92),

as formas mais sofisticadas de processos cognitivos envolvem a abstração baseada na percepção, do lado sensório, e a evolução do movimento voluntário, do lado motor. A construção de uma imagem de mundo depende de um aparato cognitivo subjacente a todas as formas de pensamento incluindo os fenômenos cognitivos, emocionais e as valorações éticas e estéticas.

Conjugando a priori as concepções de Lorentz, Riedl e Garcia, podemos perceber a nossa existência como o resultado de uma evolução que envolve sobremodo, abstração baseada na percepção, processos energéticos e cognitivos subjacente a todas as formas de pensamento.

Nas ideias de Luria (1981) já podemos divisar relevantes concepções que dão ensejo a relações como as citadas acima, ao afirmar que o desenvolvimento evolutivo dos seres humanos exige a organização das sensações. Tal organização é importante para fornecer ao cérebro as informações referentes às condições do corpo como universo "intrasomático" e do envolvimento como universo "extra-somático", com os quais produz uma motricidade adaptativa e flexível. Trata-se de uma complexa integração e associação intraneurossensorial que reflete a tendência evolutiva do processo informativo Luria (1990).

As dificuldades enfrentadas ao se tentar reproduzir o pensamento humano através de recursos de Inteligência Artificial é abordado por Faria e Rodrigues (2010) ao testarem a inteligência artificial em robôs. A I.A. produzida com conhecimentos de senso comum, organizada em modelos computacionais com tratamento seqüencial de símbolos se revelou ineficaz.

\footnotetext{
Um robô concebido nos moldes da I. A. tradicional não consegue agir eficientemente ou em tempo hábil frente a situações como interceptar um copo rolando antes de tocar o solo, pois se perde na enorme quantidade de informações e serem processadas antes da ação. Em suma, parece que nós, na realização de tarefas cotidianas, utilizamos apenas as informações adequadas para cada situação, de modo a aplicarmos, em cada caso, algum tipo de
} 
critério de relevância que inexiste nos artefatos da I. A. tradicional (FariaRodrigues, 2010: 73).

Por outro lado, Vanin (2010) aborda a forma dinâmica como ocorre a construção interna do significado em que não se encontram apenas fatores objetivos, mas também subjetividade e interatividade ao afirmar que "ao interagir com o outro, não se está apenas expressando aquilo que se pensa, mas ao mesmo tempo passa-se a influenciá-lo. A comunicação acontece em uma cadeia de intencionalidade, enfatizando a lacuna entre o que é dito e o que é entendido" (Vanin, 2010: 78). O ser humano é, portanto, diferenciado no que tange a capacidade única de criar uma interface (nota 6) singular com o outro. Tal interação o permite a faculdade de, através da percepção e intercâmbio, organizar condições únicas de compreensão e que levam a sua "interface" a se reconfigurar constantemente. Estabelece-se assim um sistema de testes e aperfeiçoamento retroalimentado (nota 7).

Neste processo, o ensino vai muito além de um conjunto de leis e regras, à guisa daquelas que tentam sustentar as interfaces computacionais da I.A. Seu papel é determinante ao orientar este processo constante de elaboração e reelaboração, inserida em um contexto histórico e cultural peculiar a condição humana. Neste processo, a de se ressaltar a sua ação como decisiva para conduzir os participantes do processo educativo e que se interagem a um "caminho diferenciado". A reflexão permanente sobre a ação educacional, enquanto sujeito do ensino, que leva a processos mentais e cognitivos apurados, em uma perspectiva dinâmica e retroalimentada, se configura essencial.

Com isso, a organização de um sistema de ensino válido, utilizando-se a lógica de Popper (1999) e que será testado pela constante interatividade e aspectos inerentes ao ambiente circundante, vai além do encadeamento de leis, fórmulas e regras em que tenta se fundamentar a I.A., Tal heurística precisa resultar em uma apropriação eficaz da consciência, tomando-se por base a condição humana e os temas que se propõe discutir, como é o caso do "objetivismo e subjetivismo" dos métodos, da própria concepção em ciências e implícitos fortemente no Ensino de Ciências. Muitas perguntas e muito há ainda para ser conjecturado sobre estes temas.

\section{Um novo rumo?}

Instigados por uma compreensão de uma "realidade híbrida", temos nos preocupado com as condições em que as noções e conceitos de ciências têm sido formados pelos alunos. É possível que, se a noção dos conceitos científicos não alcançar níveis mais genuínos, singulares e elevados do pensamento dos discentes, estes, mesmo com entendimento dos conteúdos, venham a estar excluídos como agentes transformadores da realidade, neste mundo complexo.

Assim, amparado por essa concepção, vemos os docentes em ciências como 
criadores de condições, para que as ideias surgidas como fundamento de uma nova consciência encontrem campo para o seu desenvolvimento. Pensamos que essa nova consciência se constituirá no veículo a permitir o deslocamento pelo cerne do mundo subjetivo e que, ao ser ativado, modificará todo um contexto.

Esse entendimento aumentou suas raízes com a pesquisa que realizamos recentemente, pois pudemos comprovar que os alunos se preocuparam muito mais em descrever os acontecimentos ou se reportar a noções herdadas, do que efetivamente em buscar compreensões genuínas e efetivas. Tais concepções se inscrevem no plano da consciência e são perfeitamente identificáveis.

Duas noções teóricas e que se relacionam com a psicologia da aprendizagem se juntaram as nossas reflexões. Uma delas, baseada na Teoria do Ensino Desenvolvimental de Davydov, na qual uma série de atividades de ensino deveria ser organizada a partir da autonomia do aluno, de forma a forçar o seu intelecto a se desenvolver. A outra noção, baseada na Teoria da Aprendizagem preconizada nos Parâmetros Curriculares Nacionais (Brasil, 2002) e nas ideias de Ausubel (1980) entre outros, que indicam a importância de se considerar os saberes tácitos dos alunos para uma aprendizagem efetiva e duradoura. Estes dois fatores unidos poderiam suportar um deslocamento, via aprendizagem em ciências, para um campo híbrido entre o objetivo e o subjetivo, mediante uma larga ampliação cognitiva.

Entretanto, qualquer que seja a teoria adotada, esta deverá vir acompanhada pelo desejo do aluno de compreender, sob outros aspectos e vários "prismas", a complexa realidade que o cerca. Desse modo, torna-se importante que se instigue um certo sentimento de aventura, uma disposição de busca por novos horizontes. Essas perspectivas técnicas e procedimentos de ensino talvez possam preparar para a almejada "comunhão do conhecimento", a que se refere Santos (1989) que viria permitir aos participantes do processo o entendimento e a apropriação da gama de possibilidades e riquezas que a ciência coloca à disposição do homem, inversamente aos obtidos através de um ensino estéril, que conduz a resultados pobres e destituídos de sentido.

\section{Conclusão}

Só podemos ensinar as ciências se a compreendemos em sua peculiaridade metodológica de ser. A ciência tem o seu próprio método. Percebê-lo por traz dos fenômenos, requer um olhar inclusivo, capaz de integração e vislumbre da essência que a faz existir como tal.

Manter o ensino alijado da essência das ciências, submetido a uma realidade pedagógica instaurada, muitas vezes em aulas passíveis apenas de notas e procedimentos, avaliados como adequados pelo meio acadêmico, é permanecer em uma zona de 
conforto que não condiz com os altos objetivos da educação, em termos de apropriação de mundo e cidadania.

Adicionando ao barco da concepção científica e que vem se configurando ao longo do tempo, as poderosas velas construídas e aperfeiçoadas pelas teorias de ensino e aprendizagem, da didática e da psicologia, entre várias outras, torna-se possível organizar uma embarcação vigorosa. Tal embarcação poderá nos levar como integrantes de uma mesma tripulação, em um futuro quiçá próximo, a uma terra fértil em que a ciência será concebida em sua essência, bem como amparada por um ensino que a reconheça e compreenda em sua forma de ser.

Tal organização trará novas possibilidades para a superação de um mundo antigo tão carente de equilíbrio e de harmonia, em que repousa a própria essência da ciência. Tais possibilidades surgem de um método na exploração das ciências capaz de congregar, não só os aspectos qualitativos e quantitativos de sua exploração, como também de se estruturar inteligível em uma nova perspectiva de Ensino de Ciências.

\section{Referências}

Apolinário, F.(2009). Metodologia da Ciência: filosofia e prática da pesquisa. São Paulo: Cengage Learning.

Ausubel, D.P.; Novak, J.D.; Helen, H.(1980). Psicologia Educacional. Rio de Janeiro: Interamericana.
Bakthin, M.; Volochinov, V.N. (1992). Marxismo e Filosofia da Linguagem. São Paulo: Hucitec.

BRASIL. (2002). Ministério da Educação. Secretaria da Educação Média e Tecnológica. Parâmetros Curriculares Nacionais + (PCN+) - Ciências da Natureza e suas Tecnologias. Brasília: MEC.

Davídov, V. V. (1988). La enseñanza escolar y el desarrollo psíquico. Moscou: Progreso.

Davydov, V. V. (1978). Tipos de generalización en La enseñanza. Havana: Pueblo y Educación.

Faria, L. D.; Rodrigues, C. Representações mentais e Ciência Cognitiva: dependência excessiva e problemas. Ciência e Cognição. 9, 70-76. disponível em: < http://cienciaecognição.org.br > . Acesso em: 15/01/2011.

Garcia, A. Cognição e evolução: a contribuição de Konrad Lorentz. Ciência e Cognição. 4, 89-100. Disponível em: < http://cienciaecognição.org.br>. Acesso em: 02/02/2011.

Greca, I.(Ed.). (2007). A pesquisa de ensino de ciências no Brasil e suas metodologias. Ijuí: Unijui, 2007.

Lorentz, K.(1969). Innate bases of learning. New York: Harcout, Brace e World.

Luria, A. R. (1981). Fundamentos de Neuropsicologia.Trad.de Ricardo Juarez Aranha .São Paulo: EDUSP.

Luria, A. R. (1990). Desenvolvimento Cognitivo: seus fundamentos culturais e sociais. São Paulo: Ícone.

Popper, K. R. (1999). Conhecimento Objetivo. [Trad. Milton Amado]. Belo Horizonte: Itatiaia.

Riedl, R. (1982). Evolution und Erkenntnis. Munique: Piper. 
Riedl, R. (1984). Biology of Knowleagbasis of reason. New York: Wiley. Sánchez, G.(2007). Pesquisa educacional: quantidade qualidade. São Paulo: Cortez.

\section{Santos, B. S. (1989). Introdução a uma} Ciência Pós-Moderna. Rio de Janeiro: Graal.

Serrano, G. P. (1998). Investigación cualitativa retos e interrogantes: métodos. Madri, Editorial La Muralla S.A.

Vanin, A. A. A construção (criativa) do significado: processos inferenciais e blending. Ciência e Cognição. 15, 77-93. Disponível em: <http://cienciaecognição.org.br>. Acesso em: 03/02/2011.

\section{Notas}

1 Apoptose ou morte celular programada é relativo a um fenômeno em que a célula por si só, como se fosse um ser consciente, morre para que outra mais jovem ocupe o seu lugar.

2 Heurística metabólica é um termo que criamos para possibilitar uma visualização integrada das reações no organismo, que se acoplam e se ajudam mutuamente, em escalas cada vez mais elaboradas, para a manutenção de uma vida macro, que em última análise é a vida corporal que conhecemos.

3 Difusão é o deslocamento de partículas sólidas espontaneamente de um meio com maior concentração delas para um de menor concentração.

4 Osmose compreende o deslocamento das moléculas de água, também de forma espontânea, no sentido de se igualar intrinsecamente as concentrações de dois meios distintos.

5 Parte da Biologia que estuda as hipóteses de relações evolutivas de um grupo de organismos. As relações ancestrais entre as espécies conhecidas. Atualmente é mais conhecida com o nome de Cladística. Deste ramo constam hipóteses como as de que as aves e os mamíferos se originaram a partir da evolução do grupo dos reptéis, por exemplo.

$6 \mathrm{O}$ conceito de interface possui muitos significados em várias áreas diferentes. $\mathrm{Na}$ área da comunicação é um mecanismo criado, ou estruturado capaz de promover a comunicação ou interação entre dois ou mais grupos. No caso da Ciência da Computação são dispositivos eletrônicos para trocar dados. $\mathrm{Na}$ informática é uma interconexão de dois equipamentos com diferentes funções e que não poderiam se conectar diretamente.

7 A esta etapa corresponde o que muitos cientistas vem pesquisando em relação aos modelos mentais. "Um modelo mental é uma representação interna que atua como um análogo estrutural de situações ou processos. Sua função é a de dar conta do raciocínio dos indivíduos tanto quanto tentam compreender o discurso como quando procuram explicar ou predizer o comportamento do mundo físico" (Greca,2007:394). 